\title{
Aortic clamping and stroke: Because two isn't worse doesn't mean one isn't better
}

\author{
Gaetano Paone, MD, MHSA
}

From the Division of Cardiac Surgery, Henry Ford Hospital, Detroit, Mich.

Disclosures: Author has nothing to disclose with regard to commercial support.

Received for publication March 23, 2018; accepted for publication March 27, 2018; available ahead of print April $22,2018$.

Address for reprints: Gaetano Paone, MD, MHSA, Division of Cardiac Surgery Henry Ford Hospital, 2799 West Grand Blvd, Detroit, MI 48202 (E-mail: gpaone1@comcast.net or gpaone1@hfhs.org).

J Thorac Cardiovasc Surg 2018;156:1458-9

$0022-5223 / \$ 36.00$

Copyright (c) 2018 by The American Association for Thoracic Surgery

https://doi.org/10.1016/j.jtcvs.2018.03.114

Does the use of a partial occlusion clamp (POC) increase the risk of stroke during on-pump coronary artery bypass graft surgery (CABG) when compared with a singleclamp (SC) technique? ${ }^{1-3}$ In this issue of the Journal, Alaeddine and colleagues, ${ }^{4}$ beginning with a cohort of 52,611 patients in the Society of Thoracic Surgeons Database who underwent isolated CABG between July 1, 2014, and March 31, 2015, address this question by comparing outcomes between 2 propensity-matched groups of 17,819 patients each. Despite statistically longer aortic crossclamp (74.1 vs 57.0 minutes) and cardiopulmonary bypass times (95.0 vs 89.7 minutes) in the SC group, stroke rate $(0.9 \% \mathrm{SC}, 1.1 \% \mathrm{POC})$ and mortality ( $1.3 \%$ both) were comparable between the groups.

Attempts to better understand the etiology and therefore mitigate the incidence of stroke during CABG are complicated by the relative infrequency of its occurrence and the various potential causes, which certainly include but are not confined to the choice of aortic clamping technique. 5,6 Not all strokes are embolic, with some the result of regional and/or global hypoperfusion and ischemia. Furthermore, not all strokes occur intraoperatively.

Aortic manipulation, which is generally thought responsible for the majority of strokes during $\mathrm{CABG}$, is not an isolated event but rather the summation of a number of independent actions. These may variably include cannulation, crossclamping, placement of a vent and/or cardioplegia delivery needle, use of an aortic punch or proximal anastomotic device, one or more applications of a POC, as well as the act of evaluating the aorta for areas of concern with either epiaortic ultrasound or just simple palpation.

As the authors note, the advent of transcatheter aortic valve replacement and the large volume of chest computed tomography scans have demonstrated there is very frequently significant calcification at the distal ascending aorta, arch, and origin of the great vessels and less often calcification in the midascending aorta. Might this then explain at least to some degree why aortic cannulation

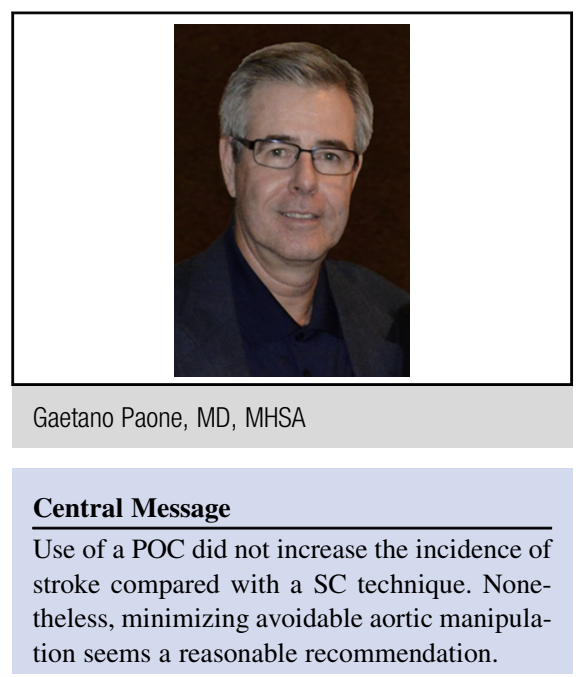

See Article page 1451.

and crossclamping seem more problematic than the use of a side-biter? In the setting of an essentially normal aorta in the area in which the POC is to be placed, there may not be a significant disadvantage to its use with regard to the risk of stroke. Certainly, this appears to be the finding of this study.

It is, however, also important to consider the effect of surgeon response to the clinical circumstances. The authors have nicely shown that most surgeons preferentially but not exclusively use one technique over the other. It is unlikely that decision making is predetermined or random but rather dictated contemporaneously by the findings in the operating room. Perhaps then the conclusion should be that given appropriate assessment of the clinical findings, either approach can be successful and equivalent with regard to the risk of stroke.

That said, what are the advantages of using a POC that warrant even the potential risk? Statistical differences in crossclamp and bypass times are unlikely of clinical relevance. Intuitively, it seems reasonable that if more aortic manipulation may have adverse consequences, then shouldn't less aortic manipulation be better?

\section{References}

1. Chu D, Schaheen L, Morell VO, Gleason TG, Cook CC, Wei LM, et al. Effect of aortic clamping strategy on postoperative stroke in coronary artery bypass grafting operations. JAMA Surg. 2016;151:59-62. 
2. Daniel WT III, Kilgo P, Puskas JD, Thourani VH, Lattouf OM, Guyton RA, et al. Trends in aortic clamp use during coronary artery bypass surgery: effect of aortic clamping strategies on neurologic outcomes. J Thorac Cardiovasc Surg. 2014; 147:652-7.

3. Araque JC, Greason KL, Li Z, Heins CN, Stulak JM, Daly RC, et al. On-pump coronary artery bypass graft operation: is one crossclamp application better than two? J Thorac Cardiovasc Surg. 2015;150:145-9.
4. Alaeddine M, Badhwar V, Grau-Sepulveda MV, Wei LM, Cook CC, Halkos ME, et al. Aortic clamping strategy and postoperative stroke. J Thorac Cardiovasc Surg. 2018;156:1451-7.e4.

5. Goto T, Maekawa K. Cerebral dysfunction after coronary artery bypass surgery. $J$ Anesth. 2014;28:242-8.

6. Engelman RM, Engelman DT. Strategies and devices to minimize stroke in adult cardiac surgery. Semin Thorac Cardiovasc Surg. 2015;27:24-9. 